\title{
El abrigo de Barranco Gómez (Castellote, Teruel), un nuevo conjunto con arte levantino en el núcleo rupestre del Guadalope $^{*}$
}

\author{
The Rock Art shelter of Barranco Gómez (Castellote, Teruel), a new Levantine Rock Art site \\ in the Guadalope nucleus
}

Manuel Bea Martínez ${ }^{a}$, Inés Domingo Sanz ${ }^{\mathrm{b}}$ y Jorge Angás Pajas

\section{RESUMEN}

Este artículo presenta un nuevo hallazgo de arte levantino en el curso medio del río Guadalope, el abrigo de Barranco Gómez, y revisa una temática particular en esta tradición artística: la recolección de la miel. Entre las novedades destaca la escena de recolección de miel mejor conservada y más compleja de este arte, con un desarrollo en dos planos diferenciados (pared y techo). En ella, un trepador, con rasgos faciales, asciende por una escala conformada por bucles de cuerda. La imagen evidencia un uso avanzado de las técnicas de fabricación y un buen conocimiento de los procedimientos de escalada. De la escena se deduce una instalación previa de la escala en lo alto de los riscos para permitir después ascender desde la base. Esta novedosa escala en estribo, va asociada a un palo que sirve de anclaje intermedio para fijarla firmemente a la roca. El conjunto incluye además arqueros en marcha, una caza de cérvidos y una cierva retrospiciente con una singular representación del hocico. El análisis estilístico y temático de las figuras humanas permite reconocer tres fases de ejecución y establecer vínculos territoriales con otros núcleos del área septentrional del arte levantino.

\begin{abstract}
This paper presents the discovery of a new site with Levantine art in the middle reach of the Guadalope river: Barranco Gómez. It also analysis a particular theme of this artistic tradition: the honey hunting scenes. Highlights of this site include the better preserved and more complex honey hunting scene of this tradition, developed in two different levels (wall and ceiling). In it, a climber, with facial traits, climbs up a rope ladder made up of rope loops. This scene shows an advanced use of rope-making techniques as well as in-depth knowledge of climbing techniques. Analysing the scene we deduce that the rope ladder was first installed from the top of the cliff to later climb from the bottom. This new sort of stirrup ladder is associated to an intermediate anchor point (a stick) firmly attaching it to the rock. Other scenes at this site include: archers marching, a deer hunt, and a hind looking back with a unique trait on its snout. The stylistic and thematic analysis of the human figures suggests, at least, three different decorative phases at this site as well as territorial connections with other areas of the northern region of Levantine rock art.
\end{abstract}

Palabras clave: península ibérica; arte levantino; Post-Paleolítico; recolección de miel; trepador; Maestrazgo; documentación multi-escala.

* El trabajo se ha financiado mediante el proyecto HAR2016-80693-P (Institució Catalana de Recerca i Estudis Avançats ICREA/Universitat de Barcelona). Se enmarca en el titulado Breaking barriers between Science and Heritage approaches to Levantine Rock Art through Archaeology, Heritage Science and IT del European Research Council (LArcHer, ERC, European Union's Horizon 2020 research and innovation programme, grant agreement No 819404) y en el proyecto HAR2017-85023-P (Universidad de Zaragoza).

a Área de Prehistoria, Dpt. d'Història, Geografia i Art. Universitat Jaume I. Av. Vicent Sos Baynat s/n. 12071 Castellón de la Plana y Grupo "P3A" (H-14-17R, Gobierno de Aragón y Fondo Social Europeo), Universidad de Zaragoza C/ Corona de Aragon 12. 50019 Zaragoza. Correo e.: bea@uji.es / manubea@unizar.es https://orcid.org/0000-0002-2841-3347

b Institució Catalana de Recerca i Estudis Avançats (ICREA). Dpt. d'Història i Arqueologia, Seminari d'Estudis i Recerques Prehistòriques (SERP). Facultat de Geografia i Història. Universitat de Barcelona. C/ Montalegre 6.08001 Barcelona. Correo e.: ines.domingo@ub.edu https://orcid.org/0000-0003-4707-8094

Escuela Técnica Superior de Ingenieros en Topografía, Geodesia y Cartografía. Universidad Politécnica de Madrid. Campus Sur UPM. Autovía de Valencia km. 7. 28031 Madrid. Correo e.: j.angas@usal.es https://orcid.org/0000-0003-3854-2158

Recibido 22-I-2021; aceptado 18-III-2021. 
Key words: Iberian peninsula; Levantine rock art; PostPalaeolithic; honey hunting; climber; Maestrazgo region; multi-scale documentation.

\section{INTRODUCCIÓN}

El objetivo de estas líneas es dar a conocer el resultado de los trabajos oficiales de documentación y estudio de esta nueva estación rupestre, vinculada al ya célebre núcleo de arte levantino del Guadalope (Teruel) (Almagro et al. 1956; Ripoll 1961; Beltrán 1968, 1993). D. Ernesto Barreda lo descubrió por casualidad en agosto de 2013. Tras comunicarlo a la Dirección General de Patrimonio Cultural del Gobierno de Aragón, técnicos facultativos del Gobierno de Aragón y uno de nosotros (M.B.) visitamos el yacimiento para certificar la autenticidad de las pinturas en marzo de 2014. La documentación del conjunto se realizó por medio de técnicas de documentación gráfica bidimensional y tridimensional que se describen en el apartado de Metodología. Esta información sirve de base para el análisis cualitativo de los motivos y temas conservados y de sus pautas de variación. Su contextualización regional nos permite confirmar una vez más las relaciones con otros núcleos del área septentrional del arte levantino, y también un uso diacrónico del yacimiento, basado en las variantes estilísticas de las figuras humanas representadas (Domingo 2005, 2006, 2012; Utrilla y Martínez Bea 2007; Martínez Bea 2009; Villaverde et al. 2012). Esta estación de Barranco Gómez, junto a temas y patrones ya clásicos en el arte levantino, tiene algunas peculiaridades estilísticas y temáticas que permiten hablar de un conjunto singular. Cabe destacar la escena de recolección de miel, la mejor conservada y con más detalle de todo el ciclo levantino. En la representación del trepador se usan diversas convenciones para las diferentes perspectivas que permiten una correcta y más realista lectura de la acción. Llama la atención la plasmación de rasgos faciales que, en algunas fases de este ciclo artístico, expresan la voluntad de individualizar al actor. En el panel 3 encontramos otro recurso técnico formal singular: la boca de la cierva se representa dejando un espacio deliberadamente sin pintar. Para este recurso no contamos con paralelos hasta el momento en el arte levantino.

La investigación del interesante núcleo de arte levantino de la cuenca media del Guadalope, donde se enmarca la estación que estudiamos (Fig. 1), se inicia con el descubrimiento y estudio del conjunto del Torico (Ortego 1946). Se le unen algunas décadas después los del Arquero, Friso Abierto del Pudial y La Vacada (Ripoll 1961) y el de Arenal de la Fonseca (González y Merino 1974). Son mucho más recientes los descubrimientos del Barranco Hondo, con sus singulares gra-

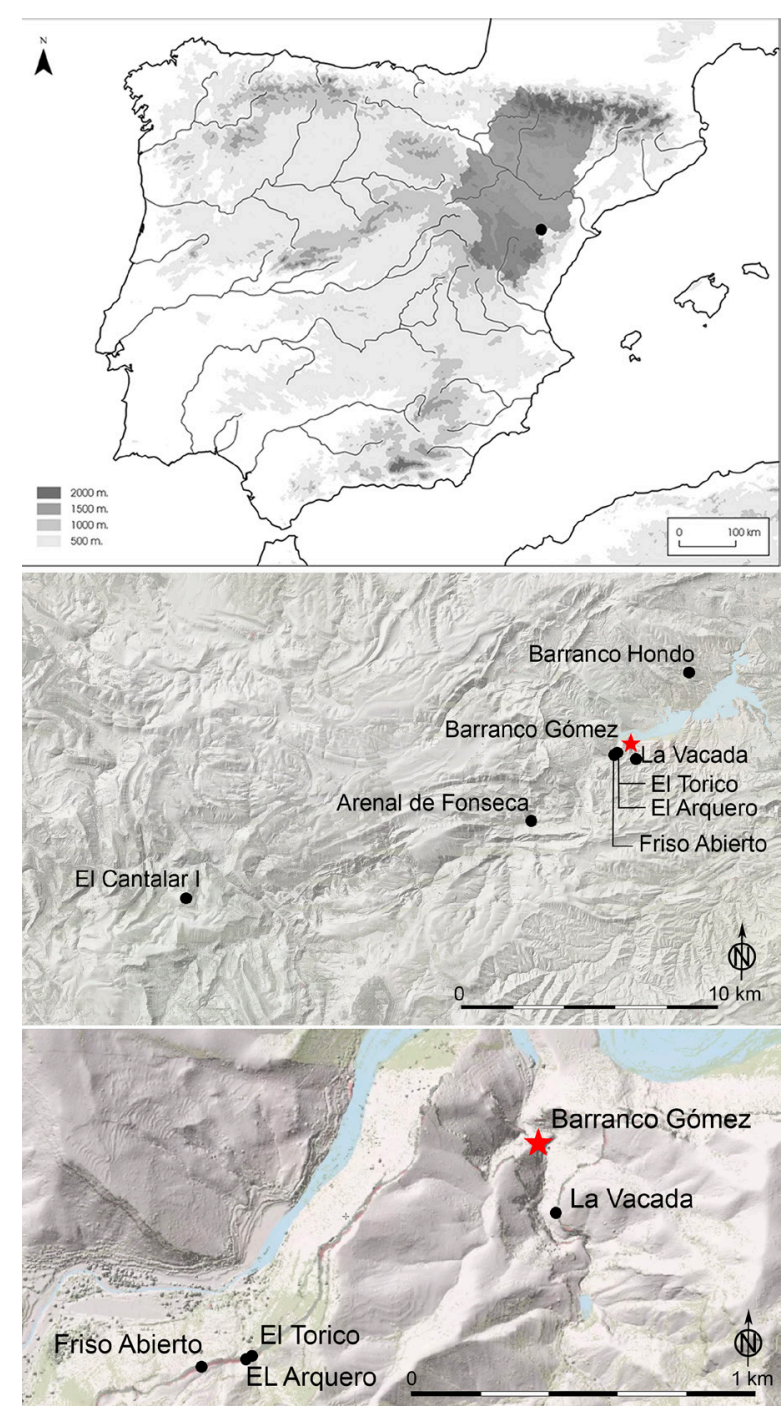

Fig. 1. Localización de la comunidad autónoma de Aragón en la península ibérica y situación del abrigo de Barranco Gómez (Castellote, Teruel). En el centro su posición y la de los conjuntos levantinos citados en el texto en el curso medio del río Guadalope. Abajo detalle de los identificados en la zona del Pudial y Barranco Gómez. Fuente: Imagen PNOA Iberpix 4. http://www.ign.es/iberpix2/visor/ (consulta 11-02-2021). En color en la edición electrónica.

bados levantinos (Utrilla y Villaverde 2004), y el del Cantalar I (Bea y Domingo 2009), el más meridional de todos. Los yacimientos de este núcleo rupestre han dado lugar a revisiones (Calvo 1993) ${ }^{1}$ que han actualizado los inventarios de conjuntos conocidos, aportando hipótesis interpretativas novedosas. Algunas se refieren a la pervivencia simbólica de las estaciones en épocas

${ }^{1}$ M. a J. Calvo, El arte rupestre postpaleolítico en Aragón. Tesis doctoral inédita. Universidad de Zaragoza, 1993. 
ya históricas, a las convenciones adoptadas para representar en perspectiva determinados motivos que modifican las identificaciones tradicionales (Martínez-Bea 2004, 2006-2008) o a las secuencias crono-estilísticas para estos conjuntos en relación al arte levantino regional (Martínez-Bea 2009)2 ${ }^{2}$ La aplicación de nuevos métodos de documentación ha permitido también identificar nuevas representaciones (Bea 2011-2012, 2012a; Utrilla et al. 2017). Otros trabajos recientes ofrecen una síntesis territorial o un corpus de conjuntos para este territorio (Bea 2012b, 2018).

En las cercanías están los conjuntos del Maestrazgo turolense y castellonense, una unidad geográfica indisociable (en especial los núcleos de La Valltorta y Gasulla y el de Morella la Vella), y los del Bajo Aragón-Matarranya. Esta zona más septentrional y próxima al curso del Ebro tiene abrigos clásicos, como Val del Charco del Agua Amarga, Plano del Pulido, Roca dels Moros, Els Gascons, los más recientes de Corrales de Poyuelo, Barranco del Muerto o Corral de las Gascas (Utrilla et al. 2014; Bea et al. 2018; Bea y Lanau 2019). El marco de referencia para analizar el nuevo hallazgo será la afinidad entre los elementos temáticos y estilísticos de todos estos núcleos (Domingo 2005, 2006, 2012; Bea et al. 2009; Villaverde et al. 2012), extensible a los de los abrigos de la cuenca del río Martín hacia el oeste y aquellos del Maestrazgo castellonense y del sur de Tarragona hacia el este.

\section{METODOLOGÍA}

La singularidad del emplazamiento de la nueva estación rupestre de Barranco Gómez (Castellote, Teruel) suponía todo un reto para la documentación de este enclave. Se trata de un frente casi vertical que hoy apenas conserva una estrecha cornisa que da acceso al conjunto. Esto determinó la aplicación de técnicas de documentación digital adaptadas a la particularidad del conjunto y del paisaje donde se integra. Las describiremos sólo de manera somera, ya que serán tratados con más detalle en otra publicación en proceso de elaboración.

Los sistemas de captura de información multi-escala se han empleado en la documentación del propio abrigo y las pinturas y, posteriormente, en la de su entorno inmediato (Anexo $\mathrm{AC} 1$ ). En el primero se han manejado técnicas de fotogrametría de espectro visible (Anexo AC1.1) y sensores multiespectrales, completadas con diferentes tipos de escáneres 3D. El avance de los sistemas de correlación automática de imágenes a

\footnotetext{
${ }^{2}$ Esta obra publica en parte la tesis doctoral inédita de Manuel Martínez-Bea: Variabilidad estilística y distribución territorial del arte rupestre levantino en Aragón. El ejemplo de La Vacada (Castellote, Teruel), defendida en la Universidad de Zaragoza en 2005.
}

través de técnicas fotogramétricas ha mejorado la aplicación de la textura en cada panel. Este factor aporta un mejor detalle frente a los sistemas de escáner 3D. Además, las diferentes variantes de escáneres empleados, tanto láser escáner terrestre (Anexo $\mathrm{AC} 1.3)$ como de luz blanca estructurada (Anexo AC1.2), permiten obtener una mejor geometría. En este caso, la cantidad de resaltes y escasa distancia al frente rocoso han provocado algunas zonas de sombra y han reducido el campo de visión de los sensores empleados. Por estas circunstancias la combinación de herramientas ha permitido obtener un mejor modelo geométrico que si solo se hubiera utilizado técnicas fotogramétricas.

Cada uno de los tres paneles en los que se divide el abrigo fue adquirido de un modo redundante con un escáner de mano Artec MHT de luz estructurada con una resolución de $500 \mu \mathrm{m}$ y con un láser escáner terrestre Leica RTC con una resolución de $5 \mathrm{~mm}$ al frente rocoso. Gracias a este último escáner hemos contextualizado, además, cada panel en el conjunto del abrigo y en parte del barranco. Como este tipo de láser alcanza hasta $130 \mathrm{~m}$ se ha podido diseñar una estrategia de estacionamientos cubriendo una amplia zona del barranco. La información contó con datos de un vuelo fotogramétrico mediante un sistema dron de ala fija con sensor GNSS RTK-PPK con una resolución de $3 \mathrm{~cm}$ píxel (Anexo AC1.5). Por último, se completó una cuadrícula de $4 \mathrm{~km}$ x $4 \mathrm{~km}$ hasta la actual cola del embalse de Santolea, como extremo norte de la documentación adquirida con datos LiDAR (Light Detection And Ranging) del Plan Nacional de Ortofotografía Aérea (PNOA) con una resolución aproximada de 1,5 m. La obtención de una nube de puntos $L i D A R$ con diferente tipo de resolución, organizada en capas, cubriendo la mayor parte del barranco, iba destinada principalmente a la estrategia de documentación multi-escala realizada en este abrigo (Anexo AC1.6).

La documentación fotográfica de los paneles se hizo mediante procedimientos convencionales junto a una pértiga asociada al uso de tableta digital para el control remoto de las cámaras. Esta información se complementó con un barrido fotogramétrico con una cámara multiespectral Parrot Sequoia $(R G B$ por las siglas de rojo, verde y azul en inglés, verde, rojo, borde del rojo e infrarrojo cercano). Su objetivo era generar un ortomosaico diferenciado por bandas para cada uno de los paneles.

La información gráfica recogida sirvió para proyectar los calcos sobre la malla mediante la técnica de unwrapping de las coordenadas UV con el software Blender. El mapeo de este tipo de coordenadas consiste en desenvolver la malla para cubrir un objeto 3D con una textura 2D. En este caso, la malla ya contaba con una textura propia. El calco se utilizó para proyectarlo en la textura existente mediante herramientas de 
clonación dentro del programa Blender, haciendo coincidir los calcos con las coordenadas UV de la textura 2D generada por fotogrametría. Los resultados finales son ortofotos rectificadas visibles y multiespectrales y la integración de los calcos digitales en los modelos tridimensionales del conjunto (Domingo et al. 2013; Angás 2019).

El análisis de todos los datos adquiridos permite trazar una estrategia interpretativa multi-escala, desde un motivo pictórico hasta el conjunto de todo el barranco y su relación geoespacial. Además la información ha sido dispuesta en una plataforma web métrica que permite analizar y extraer información on line desde las nubes de puntos distribuidas en varias capas, desde las ortofotos optimizadas en sistemas web mapping, los entornos inmersivos y modelos 3D texturizados con los calcos y desde los diferentes tipos de filtros de decorrelación además de la simulación de cualquier tipo de ángulo de luz proyectada (Anexo AC1.4).

\section{DESCRIPCIÓN DEL YACIMIENTO Y DE LOS MOTIVOS}

El abrigo de Barranco Gómez se localiza al inicio del barranco que da nombre al conjunto y que desagua directamente en el curso del río Guadalope. Este río, desarrollado en formaciones calcáreas, genera profun-

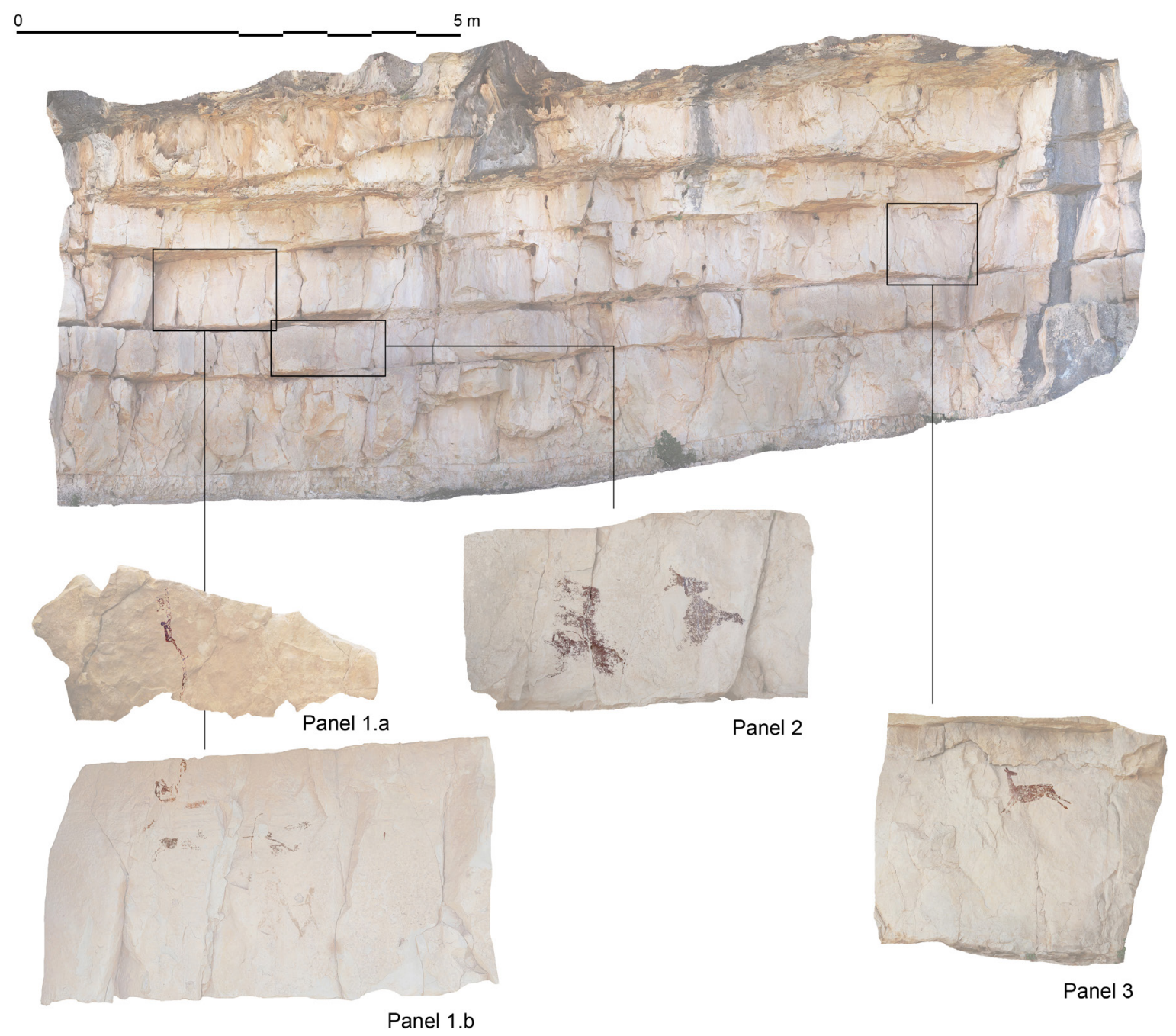

Fig. 2. Ortofoto rectificada del frente decorado del abrigo de Barranco Gómez (Castellote, Teruel), localizando los paneles decorados. El Panel 1 es el único donde se reconocen escenas (Fig. 3). Destaca la recolección de la miel, recreada en la pared y techo del soporte rocoso (Fig. 4), y una escena venatoria con arqueros (Anexo AC2). En el Panel 2 no hay formas reconocibles en los restos pictóricos conservados de gran tamaño (Fig. 5A). El Panel 3 se define por la figura de una preciosa cierva retrospiciente a la carrera (Fig. 5B). En color en la edición electrónica. 
dos encajamientos con abruptas pendientes, estrechos y cañones meandriformes (Peña-Monné et al. 1984; Peña-Monné y Sebastián 2017) que se prologan hasta alcanzar, precisamente, el ensanchamiento de la zona del embalse de Santolea al que se orienta el conjunto decorado (Fig. 1 inferior).

Los paneles fueron pintados en un frente calcáreo vertical con una visera en la parte superior compuesta por un grueso banco de calizas bioclásticas del Cretácico inferior, con una base sedimentaria que buza unos $7^{\circ}$ al SO pero cuyo desarrollo basta para proteger la pared caliza de la cota inferior. Bajo la visera, se aprecia una formación en capas calizas más estrechas de aspecto regularizado en forma de "sillares" muy singular con respecto al entorno. Su origen está en la erosión diferencial de los planos de estratificación horizontales, muy marcados por una disolución preferente siguiendo las diaclasas, así como en la afección por una red de fracturas más densa. Estas características estructurales serían la causa de la erosión diferencial observada entre la pared y la visera y una repisa o estrecha cornisa, más compactas. La pared habría sufrido una mayor alteración mecánica junto a procesos de disolución generados por el agua circulante por la red estructural.

La repisa, de unos $80 \mathrm{~cm}$ de anchura, es el único suelo conservado, y actúa de enlace entre el propio barranco y la zona del denominado Pudial, donde se localizan otros tres abrigos levantinos.

El conjunto estudiado se relaciona con el tránsito entre dos espacios diferenciados, el Pudial y el acceso al propio Barranco Gómez, a su vez, punto de paso a través del denominado "subidor de la calzada". Se conectan así la cuenca media del Guadalope y las áreas orientales del Maestrazgo castellonense (Serra Blanca y Sierra de Manadella).

La estación rupestre se encuentra en un frontal calizo de 19,65 m de longitud y 4,5 $\mathrm{m}$ de altura. La documentación se ha llevado a cabo en su tramo central de $12,4 \mathrm{~m}$ de longitud donde se distribuye el espacio decorado, dividido en tres paneles (Fig. 2). La particularidad del Panel 1 es que desarrolla la escena recreada en dos planos diferentes del soporte rocoso: la pared y el techo. Los restos, mínimos y muy dispersos, de posible pigmento podrían apuntar a una mayor superficie decorada original.

\subsection{Panel 1}

Es el panel de mayores dimensiones, el que acumula un mayor número de motivos y el único en el que es posible reconocer escenas. Además permite apreciar una diferenciación estilística de las representaciones humanas que sugiere la existencia de distintas fases decorativas del conjunto (Fig. 3). La escena principal
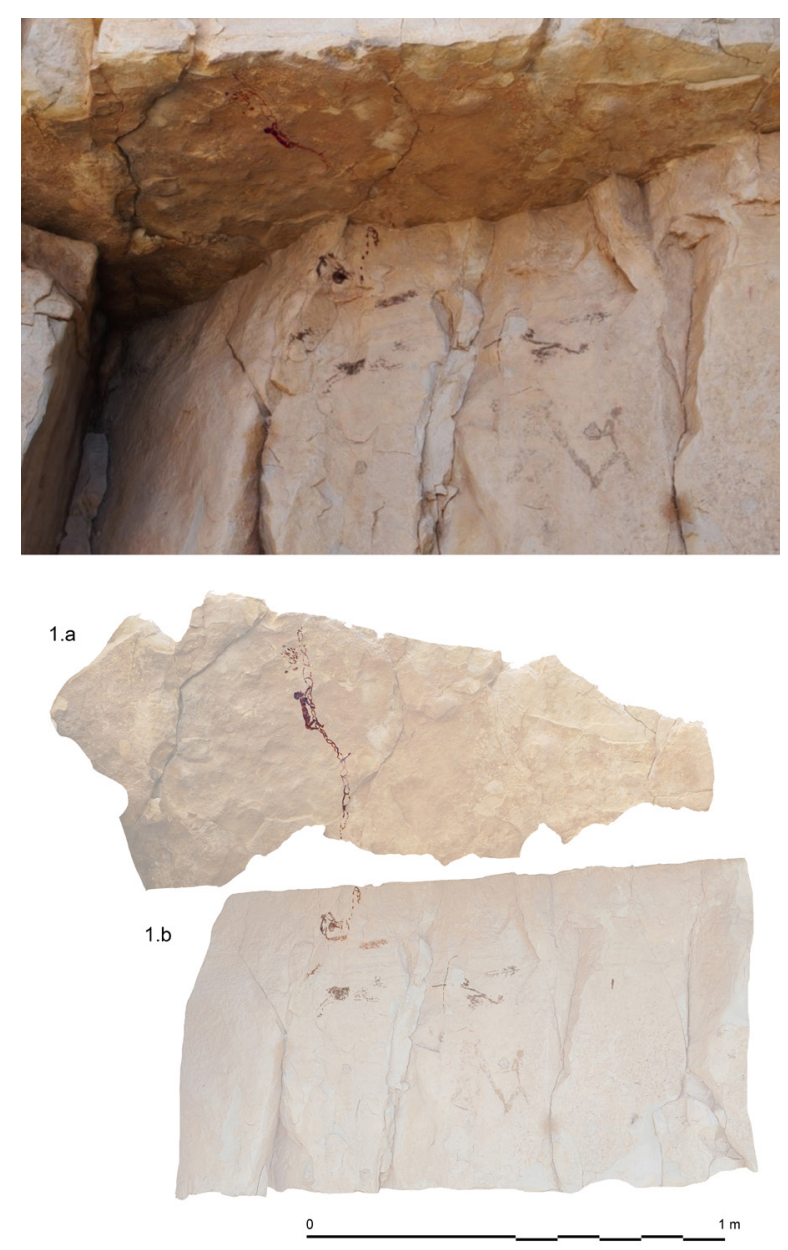

Fig. 3. Abrigo de Barranco Gómez (Castellote, Teruel). Calcos digitales de las dos escenas del Panel 1: recolección de la miel desarrollada en el techo (1.a.) y en la pared del soporte rocoso (1.b.) y escena venatoria con arqueros en la pared (1.b.). En color en la edición electrónica.

integra la morfología natural del abrigo como elemento conformante de la propia escenificación. Este aspecto se ha documentado en conjuntos cercanos, como en La Vacada, con un orificio natural de la roca a modo de colmena $^{3}$, o en El Arquero donde una protuberancia de la roca, aprovechada para simular el paisaje, daría sentido a la escena de rastreo (Bea 2012: 62-63).

Panel 1.a.: un trepador (1), una escala (2) y una colmena (3) se distribuyen en un espacio de $158 \mathrm{~cm}$ de longitud y $57 \mathrm{~cm}$ de anchura del saledizo horizontal de una cornisa en altura (Fig. 4), localizándose las pinturas a $2,79 \mathrm{~cm}$ del suelo. El trepador $(11,7 \mathrm{~cm}$ de longitud), sin representación explícita del sexo, tiene bien

\footnotetext{
3 Véase n. 2, Martínez-Bea 2005, p. 116.
} 


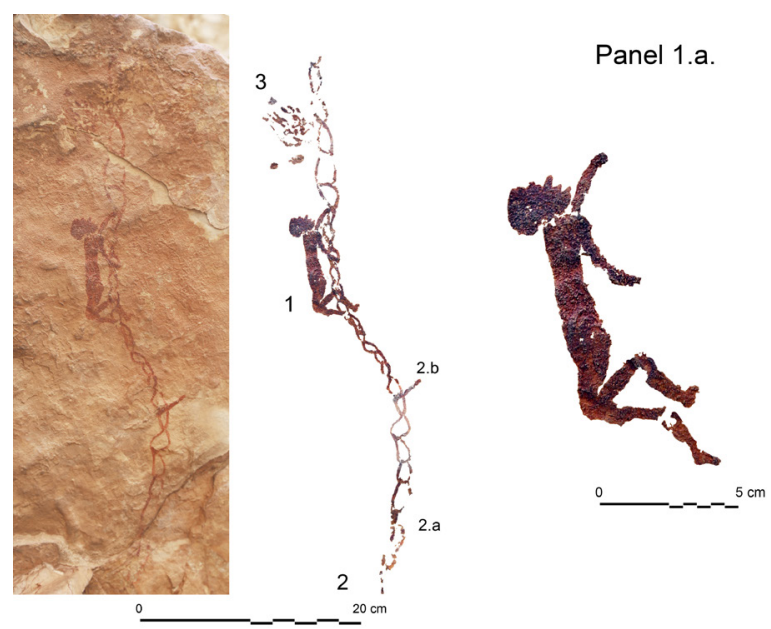

como escalones (Fig. 4.2.a). La escala debía ser vegetal, dada la forma curva de los diferentes tramos y su propio desarrollo sinuoso. En el tercio inferior identificamos un elemento lineal de $3 \mathrm{~cm}$ de longitud (Fig. 4.2.b) a modo de palo o tronco transversal insertado para asegurar la escala y evitar su oscilación durante el ascenso/descenso.

Panel 1.b.: lienzo calizo de $140 \mathrm{~cm}$ de longitud y $75 \mathrm{~cm}$ de anchura cuyo extremo inferior se localiza a $1,99 \mathrm{~m}$ de altura con respecto al suelo. En el extremo superior izquierdo de la composición, junto a la escala, una serie de trazos lineales cortos conforman un motivo de tendencia globular abierto alrededor del cual se observan hasta tres restos de aspecto puntiforme (Fig. 4.3.). Sin duda es el objetivo del trepador, una posible colmena, interpretada así teniendo en cuenta otras representaciones ya conocidas en el arte levantino, como la célebre escena de recolección de la miel de las cuevas de la Araña (Bicorp, Valencia). No obstante, las características que vemos en este caso son únicas, ya que la colmena se dibuja mediante una serie de trazos concéntricos, que recogen de forma más fidedigna la estructura de las colmenas rústicas (salvajes).

El tramo inferior de la escala ocupa parte de la pared, integrando así ambos espacios en la escena. En esta zona (Panel 1.b.) se aprecia una cierta acumulación de motivos. Junto a la escala (Fig. 4.2.) una serie de trazos cortos y gruesos de desarrollo discontinuo y longitudes entre $1,1 \mathrm{~cm}$ y $0,6 \mathrm{~cm}$ de longitud (Fig. 4.4.) parecen relacionar la escala con los motivos 5 a 8 . El motivo 5 está compuesto por dos flechas (hasta $3,7 \mathrm{~cm}$ de longitud) con emplumadura de tendencia lanceolada, un arco simple $(5,4 \mathrm{~cm}$ de longitud) y un cesto globular con asa $(3,1 \mathrm{~cm}$ de altura x $1,8 \mathrm{~cm}$ de anchura) y base ligeramente cóncava en el centro (Fig. 4.5.). Los interpretamos como los pertrechos del trepador. A la izquierda de estos objetos aparece otro antropomorfo $(5,4 \mathrm{~cm}$ de altura) de estilo afín al del trepador con brazos y piernas cruzados (Fig. 4.6.), en disposición similar a la suya. Como no tiene escala asociada podría interpretarse como un acompañante que espera sentado.

Más compleja resulta la lectura de los motivos 7 y 8 , aparentemente vinculados también con la panoplia del cazador descrita. Son pequeñas representaciones humanas $(2,7$ y $3 \mathrm{~cm}$ de altura respectivamente) de rasgos muy sintetizados, casi de tendencia al esquematismo, sin apenas detalles (aunque el motivo 8 parece llevar falda). Formalmente están alejados de los anteriores antropomorfos, aunque comparten la misma tonalidad roja oscura. Los motivos 9 y 10 se definen como restos o manchas desvaídas de color rojo más claro. Su morfología es de tendencia rectangular y desarrollo horizontal. Miden 5,7 y 7,1 cm de longitud máxima respectivamente. 
En la banda horizontal central del Panel 1.b. se desarrolla una interesante escena venatoria (Anexo AC2). Dos cuadrúpedos (motivos 11 y 12) de color rojo y orientados hacia la derecha se desplazan corriendo. Las proporciones de los elementos conservados y detalles como las orejas del 11 o la morfología alargada de la cabeza del 12 permiten definirlos como una cierva y su cría, a pesar del estado fragmentario de los motivos. Miden 18,2 cm y 7,2 cm de longitud máxima en lo conservado. A la derecha de estos motivos, separados por una ancha grieta en el soporte, se pintó un arquero orientado a la izquierda de $6,5 \mathrm{~cm}$ de altura y 17,8 $\mathrm{cm}$ de longitud máxima (desde el extremo conservado de la pierna derecha a la punta de la flecha) (Anexo AC2.13). Un desconchado ha afectado a la conservación de la cabeza, hombros y parte del brazo. El resto del cuerpo se conserva relativamente bien, lo que permite definirla como una figura estilizada de cuerpo lineal inclinado hacia delante. Ambas piernas aparecen flexionadas, en actitud dinámica, con un cierto detallismo anatómico en su representación, con muslos muy finos y una ligera volumetría en las pantorrillas. Cuenta con una serie de flecos o cintas que caen a ambos lados de la pierna desde la rodilla. El brazo derecho aparece flexionado en actitud de tensar el arco. Éste es de grandes dimensiones (14,3 cm de desarrollo) y biconvexo, y está realizado mediante un trazo lineal fino. La misma técnica se empleó en la flecha cargada que apunta directamente al cuadrúpedo 12. Inmediatamente a la derecha del arquero se observa un haz de cuatro flechas (Anexo AC2.14) dispuestas horizontalmente en paralelo, sin que resulte factible observar detalle de punta o emplumadura. El trazo lineal fino (Anexo AC2.15) que fue representado cerca del motivo zoomorfo de mayores dimensiones, quizá sea el resto de una flecha.

El tercio inferior del panel es el que presenta la lectura más compleja, ya que los motivos pictóricos están tan desvaídos que su visualización es prácticamente imposible. Sólo con tratamiento digital de la imagen es posible documentar, al menos, dos figuras parciales de arqueros. Del primero, orientado a la izquierda, sólo es reconocible parte de la pierna derecha de 14,4 $\mathrm{cm}$ de longitud. Se advierte una morfología longilínea con tratamiento volumétrico de la pantorrilla (Anexo AC2.16). A su izquierda se observan restos informes de tonalidad rojiza muy desvaídos, quizá elementos perdidos del mismo antropomorfo o tal vez de otro motivo. En la zona superior interpretamos un trazo lineal fino ligeramente curvo como parte del arco del antropomorfo. A su derecha, en la misma tonalidad y orientación, aparece un segundo arquero mejor conservado de menores dimensiones (18,8 cm de altura máxima) (Anexo AC2.17). Tiene cabeza globular, sin rasgos faciales. En la extremidad superior que está completa porta un arco y una flecha, dispuestos casi en horizontal, acompa- ñando la actitud de marcha del sujeto. El cuerpo tiene forma triangular estrechándose progresivamente hacia una cintura muy estrecha de la que arrancan dos potentes piernas abiertas en ángulo de $55^{\circ}$. La izquierda, la mejor conservada, se puede definir como modelada y con un tratamiento volumétrico de la pantorrilla bastante prominente, aunque sin llegar a poder clasificarse dentro del arquetipo robusto o "tipo Centelles". Esta pierna conecta con la del anterior arquero sin que resulte posible establecer su secuencia de ejecución. Estos arqueros son las figuras de mayores dimensiones del conjunto, ocupando la zona central del Panel 1. Se pueden clasificar dentro del arquetipo longilíneo del ciclo levantino de la zona (Utrilla y Martínez Bea 2007).

A $35 \mathrm{~cm}$ a la derecha del motivo 13, en la misma cota, se aprecia un pequeño trazo lineal (2,1 cm de longitud), aislado y en disposición vertical (motivo 18), con perfil irregular, ligeramente más ancho en la zona superior.

\subsection{Panel 2}

Tiene 95,6 $\mathrm{cm}$ de anchura y 52,5 $\mathrm{cm}$ de altura y se sitúa en un plano ligeramente inferior al Panel 1, a su derecha, y a 1,4 $\mathrm{m}$ de altura con respecto al suelo. La definición de los restos pictóricos es compleja por la falta general de formas, siquiera parciales, reconocibles conservadas (Fig. 5.A). Con todo, destacan sus dimensiones. En la zona izquierda, tres formas de tendencia rectangular paralelas en disposición casi vertical descendente hacia la derecha definen el motivo 19 (24,9 cm de altura máxima). Sus extremos derechos están unidos por otro elemento vertical de grosor similar. Parte del perfil de esas tres formas está bien delimitado lo que, unido a sus proporciones y dimensiones generales, permite pensar que fueran cuerpos de animales orientados a la izquierda. En Labarta (Adahuesca, Huesca) o en La Araña (Bicorp, Valencia) hay ejemplos de yuxtaposición vertical de tres figuraciones de animales. Sin embargo, la ausencia total de cuellos, cabezas y patas, así como los restos verticales de la misma tonalidad que unen a todas estas formas en el Panel 2 nos impide concretar esta posibilidad.

La lectura del motivo 20 (20,7 cm de altura máxima) resulta todavía más compleja por estar más desvaído que el anterior y tener una morfología menos definida. Vagamente puede recordar a la cabeza de un zoomorfo o incluso a la pata trasera de un cuadrúpedo (con corvejón señalado), pero su disposición sería extraña para ambas posibilidades y las grandísimas dimensiones que tendría la representación original hacen inviable ir más allá de su consideración como restos indeterminados.

\footnotetext{
4 Véase n. 2.
} 

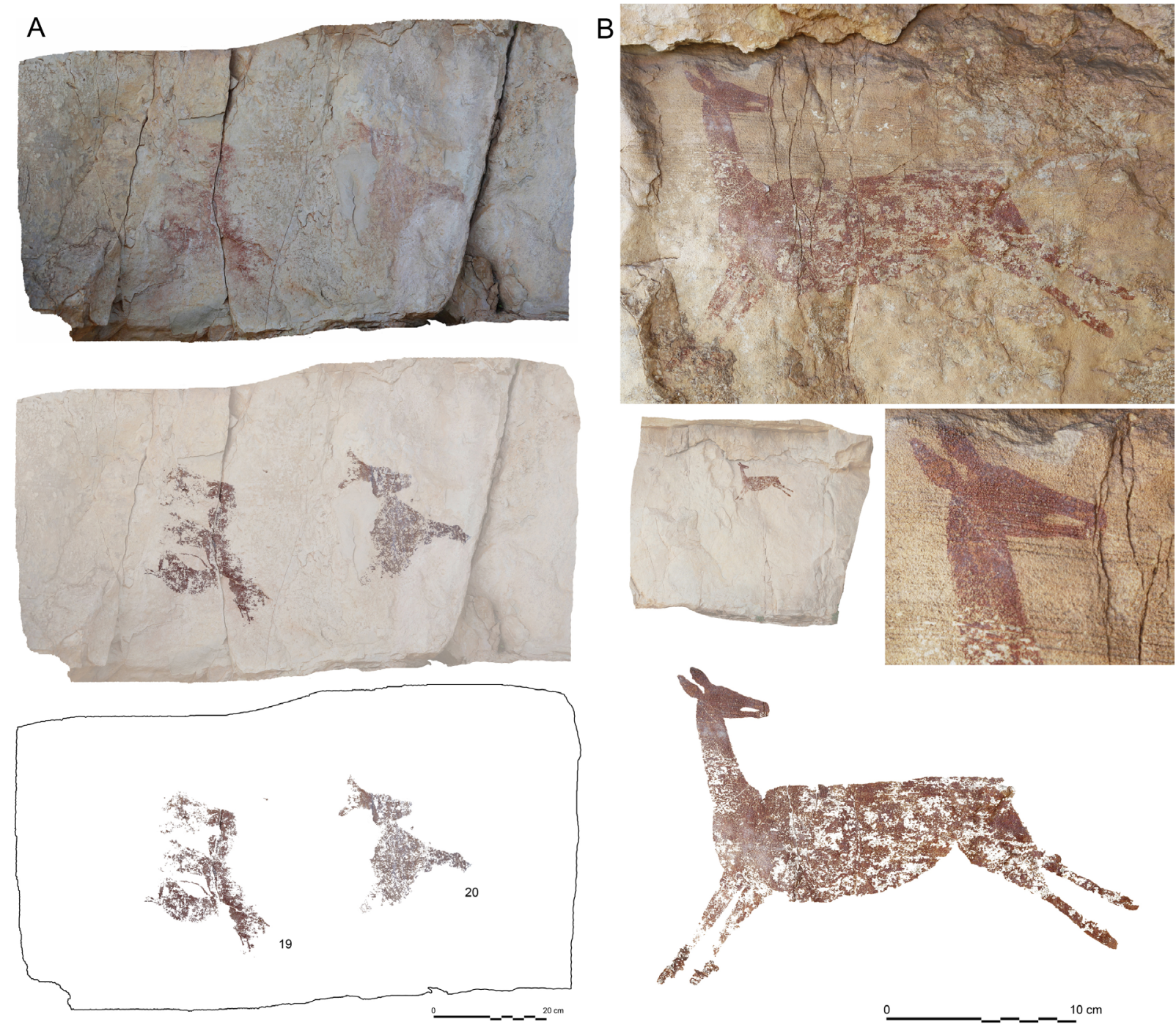

Fig. 5. Abrigo de Barranco Gómez (Castellote, Teruel). A. Fotografía y calcos del Panel 2: motivo 19 (tres formas de tendencia rectangular paralelas ¿cuerpos de animales?) y motivo 20 (restos indeterminados). B. Fotografía y calcos del Panel 3: motivo 21 (cierva retrospiciente a la carrera de color rojo oscuro).

\subsection{Panel 3}

El Panel 3 (99,8 cm de anchura x 78,7 cm de altura) se localiza a $5,97 \mathrm{~m}$ del anterior y a $1,86 \mathrm{~m}$ de altura con respecto al suelo. Su cota es similar a la del Panel 1, pero en un plano con disposición hacia el interior, por lo que la representación queda algo más oculta que el resto de paneles. En este espacio sólo se documenta una preciosa cierva retrospiciente a la carrera de color rojo oscuro (motivo 21) (Fig. 5.B). La figura de notables dimensiones (24,5 cm de longitud x 16,5 de altura) ocupa la zona alta $(2,25 \mathrm{~m}$ respecto al suelo) y central de la superficie disponible. Esta posición enfatiza su impor- tancia. Su naturalismo es casi preciosista, con proporciones correctas y detalles anatómicos que destacan una calidad de ejecución reconocible en la seguridad y finura de los trazos. El animal aparece corriendo, con las patas delanteras y traseras extendidas, algo rígidas en su concepción. En ellas, se destacan detalles como los cascos de perfil, el corvejón e incluso el espolón. La actitud de marcada huida se enfatiza mediante un cuello grácil estirado, con la cabeza vuelta hacia atrás (visualizando el peligro) y las orejas enhiestas. En la cabeza se advierten detalles naturalistas como la frente ligeramente cóncava, la quijada y el hocico, en el que 
se singulariza de forma elegante la boca. La figura se rellena en tinta plana de tonalidad uniforme en toda su superficie. Destaca una convención técnico-formal singular, sin paralelos en el arte levantino, consistente en dejar un pequeño espacio interior sin pintar en la zona del hocico.

\section{COMPOSICIONES Y PARALELOS}

La cuenca media del Guadalope concentra un cierto número de conjuntos levantinos, pero su mala conservación general impide apreciar la conformación y desarrollo de escenas. No obstante, por los restos conservados y lo que conocemos sobre el arte levantino entendemos que debieron de estar bien representadas escenas venatorias -en La Vacada, Arenal de Fonseca, El Cantalar, El Arquero- o de otra índole (arqueros en marcha, recolección, sociales, simbólicas...) en La Vacada, El Arquero, Friso Abierto o Barranco Hondo. En este contexto de registros parciales, fruto de la mala conservación, el abrigo que nos ocupa presenta el conjunto de escenas mejor conservadas en este territorio.

\subsection{Escena de recolección de la miel}

Las publicaciones sobre abrigos con arte levantino tratan el tema de la recolección de miel de forma específica (Porcar 1949; Blasco 1975; Dams y Dams 1977; Dams 1978, 1983; López-Montalvo, 2005; Martinez i Rubio 2009) o tangencial (Hernández-Pacheco 1924; Codina 1949; Beltrán 1961-1962; Beltrán y Vallespí 1960; Viñas 1979-1980, 1982; Dams 1984; Galiana1985; Beltrán y Royo 1994; Ribera et al. 1995; Escoriza 2002; Blasco 2005; Domingo 2005; Olària 2011; Lillo Bernabeu 2014; Jordán 2019; Martínez y Guillem 2019). Estos estudios suelen aludir a representaciones de recolectores de miel pero, a veces, algunas figuraciones no atestiguan de forma meridiana dicha actividad, representándose tan sólo trepadores (Cingle de Mola Remígia, Mas d'en Salvador, cueva de la Vieja de Alpera) no asociados a la típica forma de "araña", en terminología de Obermaier (citando en Beltrán 1968: 39), que Porcar (1949) interpretará como auténticos panales. Otros ejemplos, de forma intencional o fruto del deterioro de los paneles, muestran insectos y panales sin relación aparente con figuras humanas en Cova Remígia, Cingle de la Mola Remígia o Galería Alta II de Morella la Vella. Trepadores y/o recolectores de miel se documentan en las provincias de Teruel: Covacho Ahumado, Los Trepadores, Los Recolectores y La Higuera en la cuenca del Martín (Beltrán 2005; Baldellou 2010) y La Vacada y el conjunto de Barranco Gómez que nos ocupa, en la del Guadalope (Ripoll
1961; Martínez-Bea 2009); Castellón: Cova Remígia, Cingle de Mola Remígia (también referido como Cingle de la Gasulla), Cingle de l'Ermità, Mas d'en Salvador, Mas d'en Josep, Cova de la Vinya, Galería Alta II y Cova dels Rossegadors (Porcar et al. 1935; Porcar 1949; Ripoll 1963; Viñas 1982; Mateo 1995-1996; Domingo et al. 2003; Viñas et al. 2015; Martínez y Guillem 2019); Valencia: Abrigo del Ciervo, Cinto de las Letras, Cueva de la Araña, Abric de la Penya y Los Chorradores (Hernández-Pacheco 1924; Jordá y Alcácer 1951; Ribera et al. 1995; Martinez i Rubio 2009); Tarragona: Mas d'en Ramón d'en Besó (Dams 1984: 28); Albacete: Cueva de la Vieja y Minateda (Breuil 1920; Alonso y Grimal 1999). El trepador de Arpán L, en Huesca (Baldellou et al. 1993), es la representación más septentrional del arte levantino.

Los trepadores, en la mayoría de los conjuntos citados, no van acompañados por figuraciones de abejas o de panales evidentes, describibles como verdaderas escenas de recolección de miel. Dams y Dams (1977: 228) destacan que human figures climbing ropes or ladders can be seen in several Levantine sites, but cannot always be interpreted as evidence for honey gathering. Blasco (2005: 73) ha apuntado casos donde solo se representaría el enjambre. En el conjunto del arte levantino resultan relativamente escasos los abrigos con figuraciones de recolección de miel integradas por trepadores, colmenas y escalas: Cuevas de la Araña, Mas d'en Salvador, Cingle de l'Ermità, Abrigo V del Abric de la Penya, Los Chorradores, Arpán L y La Higuera (Fig. 6). Se descarta en este último caso su interpretación como escena alegórica de génesis de la Humanidad (Beltrán y Royo 1994: 3). Al margen quedarían los temas aislados interpretados como colmenas (El Cerrao), las colmenas y escala sin trepador (Abrigo del Ciervo), los enjambres (Tío Garroso, Tajo de Morella, Mas d'en Ramón d'en Besó, Remígia, Cingle de la Mola Remígia...) o incluso las escenas de recolección de miel en las que no observamos la participación de trepadores (La Vacada, Galería Alta II, Cova dels Rossegadors y posiblemente Cingle de la Mola Remígia IV). En la Cova de la Vinya, según Martínez y Guillem (2019), el supuesto panal se situaría en un árbol, lo que singularizaría esta escena respecto a las de la misma temática.

La estación de Cingle de l'Ermità es la que más similitudes presenta con la del abrigo de Barranco Gómez que estudiamos. En ambas el trepador se relaciona con bolsas o recipientes, ya sean transportados o representados al pie de la escala, donde se piensa que se guardaría la miel (Galiana, 1985: 78). Asimismo, un grupo de pequeños personajes, realizados según criterios estilísticos convencionales estilizados, parece aguardar al trepador junto a la escala, al menos en la versión documentada por Dams (1984) y asumida 

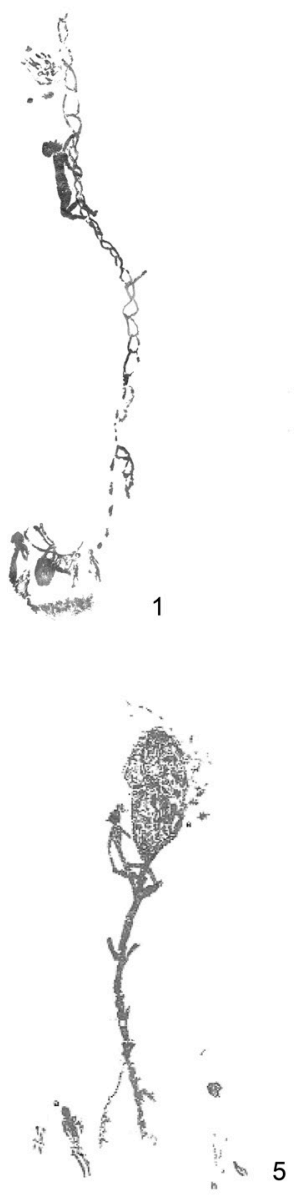
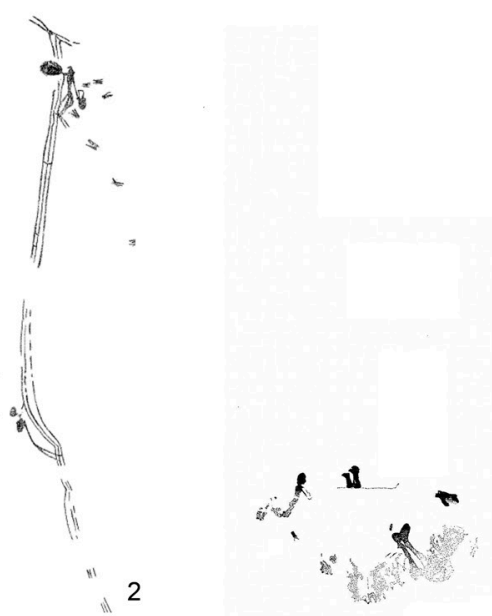

2
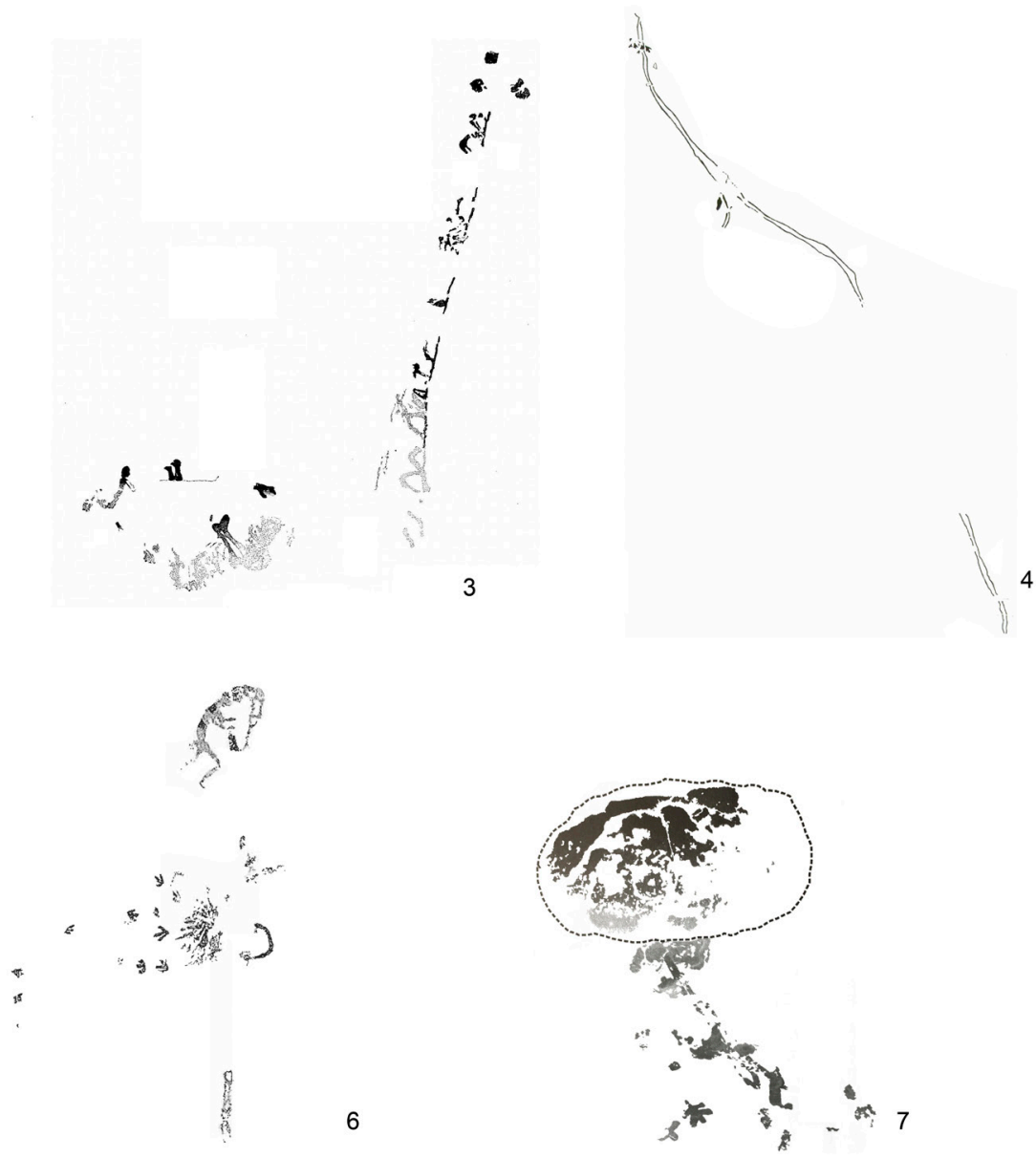

Fig. 6. Escenas de recolección de miel (con trepador, escala y colmena): 1. Barranco Gómez (en este artículo); 2. La Araña (según HernándezPacheco 1924); 3. Cingle de l’Ermità (según Viñas 1979-1980); 4. Abric V de la Penya (según Ribera et al. 1995); 5. Higuera de Estercuel (según Baldellou 2010); 6. Arpán L (según Baldellou et al. 1993); 7. Los Chorradores (según Martinez i Rubio 2009).

por Escoriza (2002). Otros estudios (Viñas 1979-1980; Guillem et al. 2010) no se refieren tan claramente a ellos, aunque apuntan que pudiera haber, en la parte inferior de la escena, una figura humana junto a algún otro resto de pintura de compleja identificación. La asociación con un grupo de antropomorfos esperando al pie de la escala con convenciones estilísticas muy sintéticas y de dimensiones reducidas aparece, no obstante, en dos de los conjuntos referidos (el de Barranco Gómez que centra estas líneas y en el abrigo de La Higuera) por lo que la actividad realizada tendría un componente social evidente.

La mayoría de los personajes que participan en este tipo de escenas suelen carecer de sexo explícito.

En general, se han descrito como 'trepador', sugiriendo directa o indirectamente, sin bases concluyen- tes, que son varones (p. ej., Hernández-Pacheco 1921: 65, 1924: 53; Obermaier 1925: 285; Ripoll 1963: 13; Beltrán 1968: 211, 1982: 52; Alonso y Grimal 1999: 30). No obstante, en algunos trabajos se habla simplemente de figuras humanas (p. ej., Viñas 1979-1980; Domingo et al. 2003), se apunta la imposibilidad de establecer diferencia de género (Ripoll 1974: 213) o se incide en la asexualidad de las representaciones (Escoriza 2002: 69; Lillo Bernabeu 2014: 873). Ello ha llevado a proponer que tanto hombres como mujeres desarrollarían actividades trepadoras. En algunos conjuntos se han identificado como mujeres e incluso se ha apuntado, también sin bases concluyentes, que ellas ejercerían en exclusiva esta actividad económica de recogida de la miel (Olària 2011: 74). En el abrigo de Barranco Gómez el sexo no se representa, lo que impide 
identificar el género de quien trepa. Es posible que los autores consideraran intranscendente esta información centrando la atención únicamente en la propia actividad. El motivo 8, a pesar de su marcada estilización y reducidas dimensiones que complican su clasificación, por su vestimenta podría ser identificable como mujer.

Todos los motivos humanos asociados a esta temática se caracterizan por sus convenciones estilísticas sintéticas, alejadas de las arquetípicas de los antropomorfos levantinos, ya sean en su variante robusta o estilizada. El trepador de Barranco Gómez sigue esta tendencia, si bien por sus detalles anatómicos y disposición corporal transciende lo visto en los demás trepadores.

\subsection{Escena de caza}

La temática venatoria es común en el ciclo levantino, aunque los ejemplos documentados en el curso medio del río Guadalope son relativamente escasos. Los únicos seguros están en El Arquero y El Cantalar I (aquí quizá como escena acumulativa) y los posibles en La Vacada y Arenal de Fonseca.

En Barranco Gómez los animales corren hacia el arquero, en lo que parece una escena de huida al ser perseguidos o espantados por algún individuo no conservado o no representado. En esa huida los animales se dirigen directamente hacia el cazador que aguarda a las presas en actitud dinámica y con el arco cargado apuntando al animal de mayores dimensiones. Una grieta del soporte parece separar los espacios de los componentes animal y humano, quizá en un intento de integrarla en la propia narración. La combinación de accidentes naturales con la acción representada se constata también en el cercano conjunto de El Arquero (Bea 2012a).

Las escenas de caza conservadas en al área cercana de estudio se componen de un reducido número de motivos. En general, es un único cazador que acecha, dispara o cobra la pieza. En Cantalar I las similitudes estilísticas son evidentes. Se comparten las mismas convenciones estilísticas y disposición dinámica del arquero (aspecto estilizado, cuerpo inclinado hacia delante, piernas flexionadas...), si bien detalles como las cintas o flecos en las pantorrillas del cazador de Barranco Gómez les diferencian. El cérvido es el objetivo de la caza en ambos conjuntos, aunque en el Barranco Gómez es una cierva y en Cantalar I un ciervo macho adulto. Aquí se interpreta como una escena acumulativa (Bea y Domingo 2009).

La figura humana es acorde con los parámetros de estilización, definidos para el arquetipo grácil: cuerpo alargado y piernas modeladas o Tipo Cingle (Domingo
2006; Utrilla y Martínez-Bea 2007)5. Tiene buenos paralelos en el ya citado conjunto de Cantalar I y en los de La Vacada, Friso Abierto, Val del Charco del Agua Amarga en la cuenca del Guadalope; en los de Tía Mona o El Garroso en la del río Martín y en los de la Cova dels Cavalls (motivos 8, 24, 35b, 50b), el Cingle de la Mola Remígia, Racó de Nando VII o Cova Remígia, en el Maestrazgo castellonense. Se caracteriza, además, por la flexibilidad adoptada en las extremidades (con brazo y piernas flexionadas) y un dinamismo enfatizado por una exagerada disposición inclinada del cuerpo que remarca la sensación de velocidad. La representación de adornos en forma de cintas o flecos que caen alrededor de la pantorrilla es igualmente interesante. Estos aspectos estilísticos se conjugan perfectamente con la aparición ocasional de ornamentos, elementos caracterizadores de este horizonte, en cabeza, cuerpo, tronco y extremidades. Destacan como paralelos diversos arqueros con representación de cintas o flecos de Tía Mona (motivos 11, 14), El Garroso (motivo 7) o El Cerrao (motivos 5, 12) en el marco geográfico occidental.

La caza en movimiento afrontando al animal que enviste aparece como una estrategia cinegética de la que participan arqueros de tipo estilizado en batidas donde los animales son empujados hacia puntos donde esperan los cazadores o bien donde los arqueros interceptan la carrera del animal. Encontramos también estas escenas en conjuntos como Cova Remígia, les Coves de la Saltadora, la Cova dels Cavalls, Val del Charco o Racó de Nando, asociados a figuras humanas de diversos estilos, por lo que podría considerarse una táctica con cierta perduración en este ciclo artístico.

\subsection{Fases decorativas}

En el conjunto decorado estudiado las representaciones humanas, generalmente utilizadas en identificación de fases, se concentran en un único panel. Sin embargo, se aprecian hasta tres morfotipos diferentes con convenciones estilísticas definidas y perfectamente asimilables a categorías regionales (Domingo 2005; Utrilla y Martínez-Bea 2007) ${ }^{6}$. Los motivos 16 y 17 son clasificables en el arquetipo grácil o longilíneo de la zona; las características de los motivos 1,6 y 13 son propias del denominado Tipo Lineal en la secuencia aragonesa o Cingle en la valenciana y el aspecto de los motivos 7 y 8 sería de tendencia Filiforme, según una

\footnotetext{
5 Véase n. 2.

${ }^{6}$ Véase n. 2.
} 
categorización (Utrilla y Martínez-Bea 2007)7 o Lineal según otra (Domingo 2005, 2006).

La seriación que se propone atiende a criterios estrictamente estilísticos, basados en el análisis de los rasgos de variación de las figuras humanas, y sigue los estudios referidos. La primera fase decorativa en el Panel 1 estaría compuesta por los motivos 16 y 17 . Son las representaciones más desvaídas y peor conservadas, pero también las de mayores dimensiones y posición central en el panel decorado. Sus convenciones estilísticas de tendencia estilizada se plasman en piernas largas, con ligera representación de la musculatura sin exageraciones, pero encorsetadas en la rigidez de los criterios canónicos del arquetipo grácil, longilíneo o tipo Centelles (Domingo 2005, 2006; Villaverde et al. 2006).

La rigidez de estos arqueros contrasta con la libertad expresiva de los motivos 1, 6 y 13, que constituirían la segunda fase decorativa. Ahora el patrón estilizado tiene un mayor dinamismo, realismo y flexibilidad de movimientos y énfasis en la acción. La plasmación de los rasgos faciales (claramente reflejados en el motivo 1) es un aspecto distintivo, cuyos paralelos esenciales están en conjuntos castellonenses como el del Cingle de Mola Remígia o Cavalls.

Los motivos 7 y 8 corresponden a la tercera fase. Ambos son de reducidas dimensiones, gran estilización, sin apenas detalles, con un alto grado de simplificación y uso de trazo simple en su confección. Su sencillez técnico-formal no excluye cierto dinamismo e incluso detalles, ya que se singularizan las diferentes partes anatómicas e incluso vestimenta. No podemos concretar si son un añadido posterior o si forman parte sincrónica de la escena de recolección con la que hay una relación directa sin evidencia de superposiciones y compartiendo la misma tonalidad que el resto de elementos figurativos. Con todo, y para esta tipología se ha apuntado "un proceso de atenuado mimetismo con respecto a las representaciones que integran las escenas a las que se adhieren" mediante el que "determinadas soluciones lineales imitan o se acercan a figuras de distintos horizontes" (Domingo et al. 2007: 185).

\section{CONCLUSIONES}

La documentación y estudio de los motivos rupestres conservados en el abrigo de Barranco Gómez nos ha permitido dar a conocer un nuevo conjunto con arte levantino en el núcleo del Guadalope. Se ha determinado el uso recurrente del abrigo a lo largo de diversas fases estilísticas, así como un contenido que combina

\footnotetext{
${ }^{7}$ Véase n. 2.
}

temas clásicos del repertorio levantino con otros más singulares. Una vez más, el análisis de los rasgos de variación de las figuras humanas actúa como principal indicador de un uso de este enclave dilatado en el tiempo sin poder, naturalmente, especificar el lapso temporal.

Debemos destacar que, atendiendo a la clasificación estilística de las representaciones humanas, no se aprecian en ellas rasgos que pudieran indicar una clara transición entre los motivos de cada uno de los tres horizontes referidos. Ni las convenciones estilísticas, ni los rasgos morfológicos, ni las temáticas permiten establecer ningún grado de relación inter-fase. Incluso se observa un cierto distanciamiento espacial, ya que las escenas protagonizadas por cada tipo humano se organizan en bandas horizontales a diferente altura. La excepción son los Motivos Filiformes asociados a los Lineales (de Aragón) o Tipo Cingle (de la secuencia valenciana). Esa estanquidad estilística no impide definir el conjunto como un espacio recurrente que habla de una evidente continuidad en el uso diacrónico del mismo.

La cierva del Panel 3 aporta la mayor novedad en las representaciones zoomorfas. Su singularidad no se encuentra en el concepto estilístico, que comparte con figuras del ámbito geográfico cercano, como el cérvido de Corral de las Gascas (Bea et al. 2018), las castellonenses de Cova dels Cavalls, Mas d'en Josep, Coves del Civil, Cova Gran del Puntal, Cova de la Taruga, Abric de la Tenalla o en la tarraconense de Cabra Feixet. La novedad se asocia más con la actitud del ejemplar, en clara huida, con la cabeza girada en un escorzo forzado a la vez que elegante. Esta convención no es demasiado habitual en las representaciones de cérvidos levantinas, aunque encontramos algunos retrospicientes (Fig. 7): un ciervo y una cierva en Cingle de Mola Remígia (Viñas y Sarriá 1978: 152); una cierva (motivo 12) en les coves del Civil (Obermaier y Wernert 1919: 21 y 23 y lám. VI); dos ciervas en las Cuevas de la Araña (motivos 37.1 y 59, esta última muy dudosa por su mala conservación) (Hernández-Pacheco 1924: 81, 94 y 111); y dos ciervas (motivos 64 y 65) en el vecino abrigo de La Vacada (Martínez-Bea 2009: 9192). Sin embargo, la mayor novedad del ejemplar de Barranco Gómez es de carácter técnico-configurativo ya que conserva un detalle interior del hocico sin pintar, que no cuenta con paralelos en el arte levantino.

La escena de recolección de miel destaca especialmente por la peculiaridad de su temática. El Barranco Gómez se une con ella al reducido número de conjuntos levantinos donde se documenta esta actividad, aportando elementos que la singularizan del resto. La utilización de dos planos diferentes (pared y techo) en el desarrollo de la escena es una novedad notable. La introducción de diferentes perspectivas abunda 

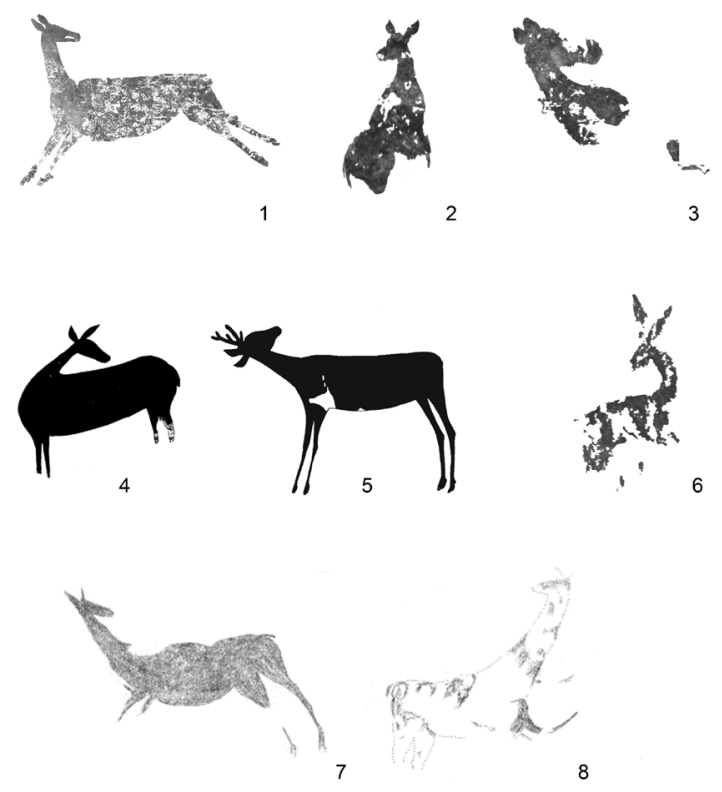

Fig. 7. Representaciones de cérvidos retrospicientes: 1. Barranco Gómez (en este artículo); 2 y 3. La Vacada (Martínez-Bea 2009); 4. El Civil (Obermaier y Wernert 1919); 5. Cingle de la Mola Remígia (Viñas y Sarriá 1978); 6. Cingle de la Mola Remígia (según Domingo, inédito); 7 y 8 . La Araña (Hernández-Pacheco 1924).

en la idea de integración del soporte como elemento conformante y descriptor de la escena. Esta circunstancia quizá haya determinado la buena conservación global de los motivos, gracias a la cual es posible apreciar perfectamente los rasgos faciales del trepador. Destacamos también el detalle en la representación de la escala, que transciende ampliamente la plasmación de meros elementos lineales, característicos de otros conjuntos. En Barranco Gómez se puede establecer el uso de escalas de cuerda formando "ochos" y el uso de estacas fijadoras para evitar el balanceo. Esta técnica ha pervivido hasta tiempos recientes en espacios diversos (Salamero y Cuchí 2019; Domingo et al. 2013: 77), y nos permite suponer que la recolección de miel sería una actividad recurrente con sistemas de acceso fijos. Además, el tipo de escala representado subraya la importancia de la tecnología de fibra, cuerda en este caso, cuyo uso debió de ser cotidiano y de aplicación muy diversa por parte de las sociedades prehistóricas. De ello da prueba el conjunto que presentamos.

Descubrimientos como el de Barranco Gómez, más allá de la singularidad de alguno de sus contenidos, remarca la necesidad de revisar nuevos y viejos territorios mediante prospecciones sistemáticas, y de tratar de redefinir el arte levantino en función de sus relaciones técnico-estilísticas y territoriales.

\section{AGRADECIMIENTOS}

Jorge Miranda y Joan Cano colaboraron en los trabajos de documentación, José Luis Peña-Monné (Universidad de Zaragoza) aportó su visión geomorfológica y José Ignacio Royo (Gobierno de Aragón) se encargó de la gestión administrativa de los permisos de estudio. Nuestro agradecimiento a los revisores del artículo y editores de la revista por los comentarios y correcciones realizadas sobre el original.

\section{ANEXOS: MATERIAL COMPLEMENTARIO}

En la edición electrónica de este artículo, disponible en libre acceso en el sitio web de la revista, se incluyen los siguientes materiales:

$\mathrm{AC1}$ : Diferentes sistemas empleados para la documentación del abrigo de Barranco Gómez: 1. Fotografía de espectro visible; 2. Escáner de luz blanca estructurada; 3. Láser escáner 3D terrestre; 4. Aplicación web gráfica y métrica para la gestión de la información; 5. Planificación del vuelo; 6. Resultados del modelo 3D del vuelo realizado con un dron de ala fija eBee X RTK-PPK con sensor visible S.O.D.A.

AC2: Abrigo de Barranco Gómez (Castellote, Teruel). Arriba: fotografía original y con tratamiento DStretch y calco de la escena de caza (11 y 12 cervato y cierva, 13 arquero, 14 y 15 flechas); abajo: fotografía original y con tratamiento DStretch con arqueros en marcha (16 y 17, 18 trazo lineal aislado).

\section{BIBLIOGRAFÍA}

Almagro, M.; Beltrán, A. y Ripoll, E. 1956: Prehistoria del Bajo Aragón. Instituto de Estudios Turolenses. Teruel.

Alonso, A. y Grimal, A. 1999: Introducción al Arte Levantino a través de una estación singular: la Cueva de La Vieja (Alpera, Albacete). Asociación Cultural Malecón. Albacete.

Angás, J. 2019: Documentación geométrica del patrimonio cultural: Análisis de las técnicas, ensayos y nuevas perspectivas. Caesaraugusta 86, Institución Fernando el Católico. Zaragoza.

Baldellou, V. 2010: "Una revisión de una escena del abrigo de La Higuera (Alcaine, Teruel)". Salduie 10: 45-51.

Baldellou, V.; Painaud, A.; Calvo, M. a J. y Ayuso, P. 1993: "Las pinturas rupestres del barranco de Arpán (Asque-Colungo, Huesca)". Bolskan 10: 31-96.

Bea, M. 2011-2012: "El conjunto con arte levantino del Friso Abierto del Pudial (Castellote, Teruel)". Salduie 11-12: 73-84.

Bea, M. 2012a: "Nuevas perspectivas de análisis para el arte levantino del Maestrazgo. Los abrigos del Arquero y del Torico (Castellote, Teruel)". Zephyrus LXX: 49-67.

Bea, M. 2012b: El arte rupestre de Castellote. Parque Cultural del Maestrazgo. Teruel.

Bea, M. 2018: "Catálogo de yacimientos: pintura". En J. M. Rodanés (ed.): Arte rupestre en Aragón. Gobierno de Aragón. Zaragoza: 103364. 
Bea, M. y Domingo, R. 2009: "Las pinturas levantinas del abrigo de El Cantalar I (Villarluengo-Montoro de Mezquita, Teruel)". Saguntum 41: 37-46.

Bea, M.; Domingo, R.; Uribe, P.; Reklaityte, I. y Fatás, L. 2009: “Actuaciones arqueológicas en los abrigos de Roca dels Moros y Els Gascons (Cretas, Teruel) y de La Fenellosa (Beceite, Teruel)". Salduie 9: 393-418.

Bea, M. y Lanau, P. 2019: "Estado actual sobre el studio del arte rupestre postpaleolítico en Aragón”. En R. Viñas (ed.): I Jornades Internacionals d'Art Rupestre de l'Arc Mediterrani de la Península Ibèrica. $X X^{e}$ Aniversari de la Declaració de Patrimoni Mundial (Montblanc, Tarragona 2019): 179-193. Montblanc.

Bea, M.; Lanau, P.; Benavente, J. A.; Villanueva, J. C. y Royo, J. I. 2018: "Novedades en el arte levantino del Bajo Aragón. Los abrigos del Corral de las Gascas y Barranco del Muerto (Alcañiz, Teruel)". En J. I. Lorenzo y J. M. Rodanés (eds.): II Congreso de Arqueología y Patrimonio Aragonés (Zaragoza 2017): 59-68. Zaragoza.

Beltrán, A. 1961-1962: "Peintures rupestres de El abrigo de Los Recolectores (Alacón, Teruel)". Bulletin de la Société Préhistorique de l'Ariège XVI-XVII: 15-50.

Beltrán, A. 1968: Arte rupestre Levantino. Universidad de Zaragoza. Zaragoza.

Beltrán, A. 1982: El arte rupestre del Levante español. Ediciones Encuentro. Madrid.

Beltrán, A. 1993. Arte prehistórico en Aragón. Ibercaja. Zaragoza.

Beltrán, A. (ed.) 2005: Corpus de arte rupestre del Parque Cultural del rio Martín. Asociación Amigos Parque Cultural del río Martín, Zaragoza.

Beltrán, A. y Royo, J. 1994: "El abrigo de La Higuera o del cabezo del Tío Martín en el Barranco de Estercuel”. Salduie 10: 45-52.

Beltrán, A. y Vallespí, E. 1960: “Otro covacho con pinturas rupestres en el Mortero de Alacón (Teruel)". Caesaraugusta 15-16: 7-18.

Blasco, C. 1975: "La recolección en el arte rupestre levantino". En Miscelánea arqueológica dedicada al Prof. Antonio Beltrán. Universidad de Zaragoza, Zaragoza: 49-58.

Blasco, C. 2005: "Arte levantino y mundo animal". Cuadernos de Arte Rupestre 2: 59-80.

Breuil, H. 1920: "Les peintures rupestres de la Péninsule Ibérique, XI, Les roches peintes de Minateda (Albacete)". L'Anthropologie XXX: $1-50$.

Codina, E. 1949. "Las pinturas rupestres del Cingle de la Mola Remigia". Boletín de la Sociedad Castellonense de Cultura XXV: 635-640

Dams, L. 1978: "Bees and honey-hunting scenes in the Mesolithic rock art of Eastern Spain". Bee World 59 (2): 45-53. https://doi.org/10.1080/0005772X.1978.11097692

Dams, L. 1983: “Abeilles et recolte du miel dans l'Art rupestre du Levant espagnol”. En Homenaje al prof. Martín Almagro Basch I. Ministerio de Cultura. Madrid: 363-369.

Dams, L. 1984: Les peintures rupestres du Levant Espagnol. Éd. Picard. Paris.

Dams, M. y Dams, L. 1977: "Spanish rock art depicting honey-gathering during the Mesolithic". Nature 268: 228-230. https://doi.org/10.1038/268228a0

Domingo, I. 2005: Técnica de ejecución de la figura en el arte rupestre levantino. Hacia una definición actualizada del concepto de estilo: validez y limitaciones. Tesis doctoral, Universitat de València. València. http://hdl.handle.net/10803/10173

Domingo, I. 2006: "La figura humana, paradigma de continuidad y cambio en el arte rupestre levantino". Archivo de Prehistoria Levantina XXVI: 161-191.

Domingo, I. 2012: "Human Figures, techniques and territories: towards a technical redefinition of Levantine rock art”. En J. J. García, H. Collado y G. Nash (eds.): The Levantine Question: Post-Palaeolithic rock art in the Iberian Peninsula. Archaeolingua. Budapest: 117-144.

Domingo, I.; López-Montalvo, E.; Villaverde, V.; Guillem, P. y MartínezValle, R. 2003: "Las pinturas rupestres del Cingle del Mas d'en Josep (Tírig, Castelló). Consideraciones sobre la territorialización del arte levantino a partir del análisis de las figuras de bóvidos y jabalíes". Saguntum 35: 9-49.
Domingo, I; López-Montalvo, E; Villaverde, V. y Martínez, R. 2007: Los Abrigos VII, VIII y IX de les Coves de la Saltadora. Generalitat Valenciana, Conselleria de Cultura, Educació i Esport. Valencia.

Domingo, I.; Rives, B.; Roman, D. y Rubio, R. 2013. Imágenes en la piedra. Arte rupestre en el abrigo de las Monteses y su entorno (Jalance). Ayuntamiento de Jalance/Ministerio de Cultura. Valencia.

Domingo, I.; Villaverde, V.; López-Montalvo, E.; Lerma, J. L. y Cabrelles, M. 2013: "Latest developments in rock art recording: Towards an integral documentation of Levantine rock art sites combining 2D and 3D recording techniques". Journal of Archaeological Science 40 (4): 1879-1889. https://doi.org/10.1016/j.jas.2012.11.024

Escoriza, T. 2002: La representación del cuerpo femenino. Mujer y arte rupestre levantino del Arco Mediterráneo de la Península Ibérica. British Archaeological Reports International Series 1082, BAR Publishing. Oxford.

Galiana, M. ${ }^{\text {a }}$ F. 1985: “Contribución al arte rupestre levantino. Análisis etnográfico de las figuras antropomorfas". Lucentum IV: 55-87. https://doi.org/10.14198/lvcentvm1985.4.04

González, F. y Merino, M. ${ }^{\text {a }}$ V. 1974: "Pinturas rupestres de Ladruñán: el cazador de la Fonseca". Boletín Informativo de la Excelentísima Diputación Provincial de Teruel 33 (1): 42-43.

Guillem, P.; Martínez-Valle, R. y Villaverde, V. 2011: Arte rupestre en el riu de Les Coves (Castellón). Monografías del Instituto de Arte Rupestre 3, Generalitat Valenciana. Valencia.

Hernández-Pacheco, E. 1921: "Escena pictórica con representaciones de insectos de época paleolítica". Real Sociedad Española de Historia Natural, Tomo Extraordinario 50 Aniversario, Museo Nacional de Ciencias Naturales. Madrid. 62-67.

Hernández-Pacheco, E. 1924: Las pinturas prehistóricas de las Cuevas de la Araña (Valencia). Memoria 34 Comisión de Investigaciones Paleontológicas y Prehistóricas, Junta para Ampliación de Estudios e Investigaciones Científicas, Museo Nacional de Ciencias Naturales. Madrid.

Jordá, F. y Alcácer, J. 1951: Las pinturas rupestres de Dos Aguas (Valencia). Serie de Trabajos Varios 16, Servicio de Investigación Prehistórica. CSIC-Instituto de Arqueología Rodrigo Caro. Valencia.

Jordán, J. F. 2019: "Arte rupestre levantino: mitograma y territorios. Minateda como encrucijada". En R. Viñas (ed.): I Jornades Internacionals d'Art Rupestre de l'Arc Mediterrani de la Peninsula Iberica (Montblanc, 25-27 de octubre de 2019): 265-295. Montblanc.

Lillo Bernabeu, M. 2014: La imagen de la mujer en el arte prehistórico del Arco mediterráneo de la Península Ibérica. Tesis Doctoral, Universidad de Alicante, Alicante. http://hdl.handle.net/10045/45725

López-Montalvo, E. 2005: "La caza y la recolección en el Arte Levantino". En R. Martínez Valle (ed.): Arte rupestre en la Comunidad Valenciana. Generalitat Valenciana, Valencia: 265-278.

Martínez Bea, M. 2004: "Perduración ritual de los abrigos pintados: el ejemplo de La Vacada (Castellote, Teruel)". Trabajos de Prehistoria 61 (2): 111-125. https://doi.org/10.3989/tp.2004.v61.i2.46

Martínez Bea, M. 2006-2008: “Aproximación al estudio de la perspectiva en el arte levatino". Bolskan 23: 127-134.

Martínez Bea, M. 2009: Las pinturas rupestres del abrigo de La Vacada. Monografías Arqueológicas 43, Universidad de Zaragoza. Zaragoza.

Martínez i Rubio, T. 2009: "El abrigo de los Chorradores (Millares, València). Una nueva representación de recolección de miel a orillas del Rio Júcar". En J.-A. López, R. Martínez-Valle y C. Matamoros (eds.): El arte rupestre del Arco Mediterráneo de la Península Ibérica: 10 años en la lista del Patrimonio Mundial de la UNESCO. Generalitat Valenciana. Valencia: 95-104.

Martínez-Valle, R. y Guillem, P. M. (eds.) 2019: Arte rupestre en Morella la Vella. Ayuntamiento de Morella. Morella.

Mateo, M. A. 1995-1996: "La vida cotidiana en el arte rupestre levantino". Anales de Prehistoria y Arqueología 11-12: 79-90.

Obermaier, H. 1925: El Hombre Fósil. Memoria 9 Comisión de Investigaciones Paleontológicas y Prehistóricas, Junta para la Ampliación de Estudios e Investigaciones Científicas, Museo Nacional de Ciencias Naturales. Madrid.

Obermaier, H. y Wernert, P. 1919: Las pinturas rupestres del barranco de Valltorta (Castellón). Memoria 23 Comisión de Investigaciones Paleontológicas y Prehistóricas, Junta para la Ampliación de Estudios 
e Investigaciones Científicas, Museo Nacional de Ciencias Naturales. Madrid.

Olària, C. 2011: Del sexo invisible al sexo visible. Las imágenes femeninas postpaleolíticas del Mediterráneo peninsular. Serie de Prehistòria i Arqueologia, Diputació de Castelló. Castelló.

Ortego, T. 1946: "Nuevos hallazgos rupestres en la provincia de Teruel. La cueva del Pudial, en Ladruñán”. Archivo Español de Arqueología XIX: 155-159.

Peña-Monné, J. L.; Gutiérrez, M.; Ibáñez, M. ${ }^{a}$ J.; Lozano, M. ${ }^{a}$ V.; Rodríguez, J.; Sánchez, M. y Yetano, L. M. 1984: Geomorfología de la provincia Teruel. Instituto de Estudios Turolenses. Teruel.

Peña-Monné, J. L. y Sebastián, M. 2017: “El marco geográfico y geomorfológico de los abrigos del Arenal de Fonseca (valle del río Guadalope)". En P. Utrilla, R. Domingo y M. Bea. (eds.): El Arenal de Fonseca (Castellote, Teruel). Ocupaciones prehistóricas del Gravetiense al Neolítico. Monografías Arqueológicas 52, Universidad de Zaragoza. Zaragoza: 153-158.

Porcar, J. 1949: "Iconografía rupestre de Gasulla y Valltorta. Representación de insectos. Características y particularidades que ofrecen". Boletín de la Sociedad Castellonense de Cultura XXV: 169-182.

Porcar, J.; Obermaier, H. y Breuil, H. 1935: Excavaciones en la Cueva Remigia (Castellón). Memorias de la Junta Superior del Tesoro Artístico 136, Sección de Excavaciones. Madrid.

Ribera, A.; Galiana, M. ${ }^{\text {a }}$ F.; Torregrosa, P. y Llin, V. 1995: "L'Abric de la Penya. Noves pintures rupestres postpaleolítiques a Moixent (Valencia)". Recerques del Museu d'Alcoi 4: 121-133.

Ripoll, E. 1961: Los abrigos pintados de los alrededores de Santolea (Teruel). Monografías de Arte Rupestre 1, Instituto de Prehistoria y Arqueología, Diputación Provincial de Barcelona y Wenner Gren Foundation. Barcelona.

Ripoll, E. 1963: Pinturas rupestres de la Gasulla (Castellón). Monografía de Arte Rupestre 2, Instituto de Prehistoria y Arqueología, Diputación Provincial de Barcelona y Wenner Gren Foundation. Barcelona.

Ripoll, E. 1974: "Formas de vida económica en el arte rupestre levantino". Zephyrus XXV: 209-223.
Salamero, E. y Cuchí, J. A. 2019: “Miel salvaje en el Alto Aragón?”. Bolskan 27: 157-167.

Utrilla, P.; Domingo, R. y Bea, M. 2017: El Arenal de la Fonseca (Castellote, Teruel). Ocupaciones prehistóricas del Gravetiense al Neolítico. Monografías Arqueológicas 52, Universidad de Zaragoza. Zaragoza.

Utrilla, P. y Martínez-Bea, M. 2007: "La figura humana en el arte rupestre aragonés". Cuadernos de Arte Rupestre 4: 161-203.

Utrilla, P.; Picazo, J. V.; Bea, M. y Calaf, J. 2014: "New Levantine paintings in Lower Aragón. The boomerang users of the Poyuelo shelter (Torrecilla de Alcañiz, Teruel, Spain)". International Newsletter on Rock Art. INORA 70: 21-26.

Utrilla, P. y Villaverde, V. 2004: Los grabados levantinos del Barranco Hondo (Castellote, Teruel). Monografías del Patrimonio Aragonés 1, Gobierno de Aragón. Zaragoza.

Villaverde, V.; Guillem, P. y Martínez-Valle, R. 2006: "El horizonte gráfico Centelles y su posición en la secuencia del arte levantino del Maestrazgo". Zephyrus LIX: 181-198.

Villaverde, V.; Martínez, R.; Guillem, P.; López, E. y Domingo, I. 2012: "What do we mean by Levantine rock art?". En J. J. García, H. Collado y G. Nash (eds.): The Levantine Question: Post-Palaeolithic rock art in the Iberian Peninsula. Archaeolingua. Budapest: 81-115.

Viñas, R. 1979-1980: "Figuras inéditas en el Barranco de la Valltorta (Castelló)". Ampuries 41-42: 1-34.

Viñas, R. 1982: La Valltorta. Arte rupestre del levante español. Ed. Castell. Barcelona.

Viñas, R.; Morote, J. G. y Rubio, A. 2015: El proyecto: Arte rupestre del parque Valltorta-Gassulla y zona Norte de Castellón (Campaña 2008-2009). Monografies de Prehistòria i Arqueologia Castellonenques, Servei d'Investigacions Paleontològiques i Prehistòriques. Castellón.

Viñas, R. y Sarriá, E. 1978: "Las representaciones faunísticas del término de Ares del Maestre (Castellón de la Plana)". Cuadernos de Prehistoria y Arqueología Castellonenses 5: 143-162. 